\title{
Serebrovasküler Hastalığa Bağlı Kortikal Körlük: Bir Olgu Sunumu
}

\author{
Cortical Blindness Induced by Cerebrovascular Disease: A Case Report
}

\section{Mustafa Ümit Can DÖLEK ${ }^{1}$ (D), Serdar ÖZDEMiR ${ }^{1}$ (D), Hatice Șeyma AKÇA ${ }^{1}$ (D, Abdullah ALGIN ${ }^{1}$ (D), Serkan Emre EROĞLU ${ }^{1}$ (D), Murat GÖL ${ }^{2}$ (D)}

'Sağlık Bilimleri Üniversitesi, Ümraniye Eğitim ve Araștırma Hastanesi, Acil Tıp Anabilim Dalı, İstanbul, Türkiye ${ }^{2}$ Marmara Üniversitesi Tıp Fakültesi, Acil Tıp Anabilim Dalı, İstanbul, Türkiye

ORCID ID: Mustafa Ümit Can Dölek 0000-0003-2895-7472, Serdar Özdemir 0000-0002-6186-6110, Hatice Șeyma Akça 0000-0003-2823-9577, Abdullah Algın 0000-0002-9016-9701, Serkan Emre Eroğlu 0000-0002-3183-3713, Murat Göl 0000-0002-8373-7934

Bu makaleye yapılacak atıf: Dölek MÜC ve ark. Serebrovasküler Hastalığa Bağlı Kortikal Körlük: Bir Olgu Sunumu. Med J West Black Sea. 2021;5(2):305-308.

Sorumlu Yazar

Serdar Özdemir

E-posta

dr.serdar55@hotmail.com öz

Anton-Babinski sendromu, bilateral kortikal körlük, görsel konfabülasyon ve anosognozi ile karakterize, nadir görülen bir nöropsikiyatrik klinik antitedir. Bu olgu sunumunda 93 yaşında bilateral posterior serebellar arter oklüzyonu olan Anton-Babinski Sendromu olgusunu güncel literatür eşliğinde sunduk. Esas olarak her iki oksipital lobun iskemik veya hemorajik inmesi ile ilişkili olan bu durumun tanınması klinik olarak önemlidir.

Anahtar Sözcükler: Nörolojik belirtiler, Duygu bozuklukları, Görme bozuklukları, Körlük, Kortikal körlük

\section{ABSTRACT}

Anton-Babinski syndrome is a rare neuropsychiatric clinical entity characterized by bilateral cortical blindness, visual confabulation and anosognosia. In this case report, we present a 93-year-old case of Anton-Babinski Syndrome with bilateral posterior cerebellar artery occlusion in the light of current literature. It is clinically important to recognize this condition, which is mainly associated with ischemic or hemorrhagic stroke of both occipital lobes.

Keywords: Neurologic manifestations, Sensation disorders, Vision disorders, Blindness cortical blindness 


\section{GiRiş}

Kortikal körlük vizüel ön yolun korunduğu, bilateral oksipital lob lezyonlarının neden olduğu görme kaybını ifade eder (1). Anton-Babinski sendromu (görsel anosognozi); göremeyen hasta tarafından görme kaybının reddi ile karakterize, kortikal körlüğün nadir bir komplikasyonudur (2).

Görsel anosognozinin literatürdeki ilk tanımı, körlüğünü reddeden bir asilzadeyi tanımlayan Fransız Rönesans yazarı Michel de Montaigne tarafından 16. Yüzyılda yapılmıştır. 1895'te Avusturyalı psikiyatrist ve nörolog Gabriel Anton, her iki temporal lobunda bir lezyon nedeniyle kortikal sağırlıkla birlikte anosognozisi olan 69 yaşındaki Juliane Hochriehser vakasını tanımlamıştı. Anton duyu kusurlarını reddeden, körlük ve sağırlık vakalarından da bahsetmiştir. 1914'te Fransız-Polonyalı nörolog Joseph François Babinski, hemiplejili hastalarda eksikliğin farkında olmamasını tanımlamak için ilk kez "anosognozi" terimini kullanmıştır (1). Oksipital lob enfarktüsü ilk kez Mayen tarafından posterior serebral arter dallarının oklüzyonuna bağlı olarak 1920 yılında bildirilmiştir (3).

Literatürde tanımlanmış Anton-Babinski sendromlu olgularda etiyolojik en sık neden bilateral oksipital lob tutulumlu iskemik inmedir (3). Bilateral posterior serebellar arter oklüzyonu bağlı Anton-Babinski sendromu gelişen 93 yaşındaki kadın hastayı literatüre katkı amaçlı sunuyoruz.

\section{OLGU SUNUMU}

Doksan üç yaşında kadın hasta yakınları tarafından bulantı, kusma, ayağı takııp düşme şikayetleriyle kliniğimize başvurdu. Özgeçmişinde kronik böbrek hasarı, hipertansiyon ve atriyal fibrilasyon öyküsü olan hasta düzenli olarak asetilsalisik asit, perindopril indapamid kullanıyordu. Hastanın yaklaşık bir haftadır bulantı, denge kaybının olduğu ve asetilsalisik asiti düzensiz kullandığı öğrenildi. Hastanın başvuru sırasında nabzı 72/dakika, arteriyel kan basıncı 196/102 mm/Hg olarak ölçülürken, Glaskow koma skoru 15 olarak değerlendirildi. Hastanın elektrokardiyogramında atriyal fibrilasyon saptandı. Yapılan muayenede bilinci açık, yer zaman oryantasyonu, anlaması ve konuşması doğaldı. Ancak göz teması kurmuyordu. Gözler spontan hareketli ve bilateral pupil ışık refleksi pozitifti. Görme keskinliği azalmıştı. Elli santimetre mesafeden parmak hareketlerini ayırt edemiyordu. Motor ve duyu kaybı tespit edilmedi. Yapılan eksternal muayenede travmatik lezyon izlenmedi.

Hastanın laboratuvar incelemesinde lökosit sayısı 15,36 $10^{3} / \mathrm{mm}^{3}$, hemoglobin değeri $11,9 \mathrm{~g} / \mathrm{dl}$, trombosit sayısı 220 $10^{3} / \mathrm{mm}^{3}$, kreatinini $1,41 \mathrm{mg} / \mathrm{dl}$, kan üre azotu $34 \mathrm{mg} / \mathrm{dl}$ olarak tespit edildi. Ayrıca hastada hepatit B yüzey antijeni 605 S/CO (negatif değeri 0-1 S/CO), hepatit B yüzey antikoru $10,6 \mathrm{mlU} / \mathrm{mL}$ (negatif değeri 0-9 $\mathrm{mlU} / \mathrm{mL}$ ) ölçüldü. Karaciğer enzim testleri ve kanama zamanı normal aralıktaydı. Hastanın kontrastsız beyin tomografisinde serebral sulkus- ların derinlik ve genişlikleri serebral atrofi ile uyumluydu. Tomografide başka patolojik bulgu izlenmedi. Beyin difüzyon manyetik rezonans görüntülemesinde bilateral oksipital lobu tutan akut enfarkt izlendi. Kontrastlı manyetik rezonans anjiyografi görüntülemede bilateral posterior serebral arterlerde dolum defekti izlendi (Şekil 1).

Anton-Babinski sendromu ve hepatit-B enfeksiyonu nedeniyle hasta hastaneye yatııldı. Enoksaparin $2 \mathrm{mg} / \mathrm{kg} / \mathrm{gün}$ (200 ünite anti-factor Xa) subkutan olarak günde iki doz şeklinde başlandı ve 7 gün devam edildi. Yedi günlük klinik takibin ardından hastanın görme keskinliğinde düzelme saptanmadı. Hastanın tedavisi günde bir kez $30 \mathrm{mg}$ oral edoksaban ve $100 \mathrm{mg}$ asetilsalisilik asit olarak düzenlendi. Hasta yakınları olası travmalar açısından bilgilendirilerek taburcu edildi.

\section{TARTIȘMA}

Görsel olarak cisimleri tanıma yeteneği vizüel yol, serebral korteksin primer görme alanı, oksipital lobdaki sekonder vizüel korteks ile dominant hemisferin anguler girusunun bütünlüğüne bağlıdır (4). Kortikal görme kaybının eşlik ettiği klinik antite olan Anton-Babinski sendromunda anazognozi gelişim nedeni tam olarak aydınlatılamamıştır. Bununla birlikte, görsel alan ile dil alanı arasındaki bağlantının kesilmesi, sekonder vizüel yolun aşırı hareketi, bilinçli farkındalık sistemi ya da nöropsikiyatik mekanizmalar sendromun gelişiminde sorumlu tutulmaktadır $(1,5)$.

Anton-Babinski sendromunun etiyolojisinde en sık neden bilateral oksipital lobu tutan iskemik inme olup multiple skleroz, MELAS (mitokondriyal miyopati, ensefalopati, laktik asidoz, strok benzeri epizod) kardiyak cerrahi, preeklampsi, obstetrik kanamalar, kafa travması, adrenolokodistro$\mathrm{fi}$, hipertansif ensefalopati, otoimmun vaskulitler, progresif multifokal lökoensefalopati gibi nedenlerle gelişen olgular literatürde bildirilmiştir (1). Bizim olgumuzda da etiyolojide bilaterel posterior serebral arter oklüzyonunun neden olduğu bilateral oksipital lob enfarktürü yer almaktaydı.

Sendromun tedavisi altta yatan nedene yönelik olmalıdır. İnmeye bağı Anton-Babinski sendromu gelişmişse antitrombosit ajanlarla tedavi edilebilir (6). Erken başvuruda tek taraflı posterior serebral arter tıkanıklıklarında trombolitik ve trombektomi tedavisinden fayda görülebilir (7). Bizim olgumuzda kliniğin yaklaşık bir hafta önce başlamış olması, enfarkt alanının görece büyük olması, hastanın yaşı, oklüde arterin mekanik trombektomiye uygun olmaması gibi nedenlerle trombolitik tedavi veya trombektomi uygulanmamıştır.

Oksipital alanda bilateral tutulumlara bağlı olarak bilinçli ya da bilinçsiz olarak görme azlığı gelişebilmektedir $(2,3,5,8)$. Misra ve ark.nın Hindistan'dan bildirdikleri preeklamsi hastasında bilateral oksipital lobda enfarkta bağlı gelişen Anton-Babinski sendromunda ise hasta sekelsiz iyileşmiştir (3). Amerika Birleşik Devletlerinden bildirilen 50 yaşında sistemik lupus eritamotazis hastasında gelişen Anton-Babinski 

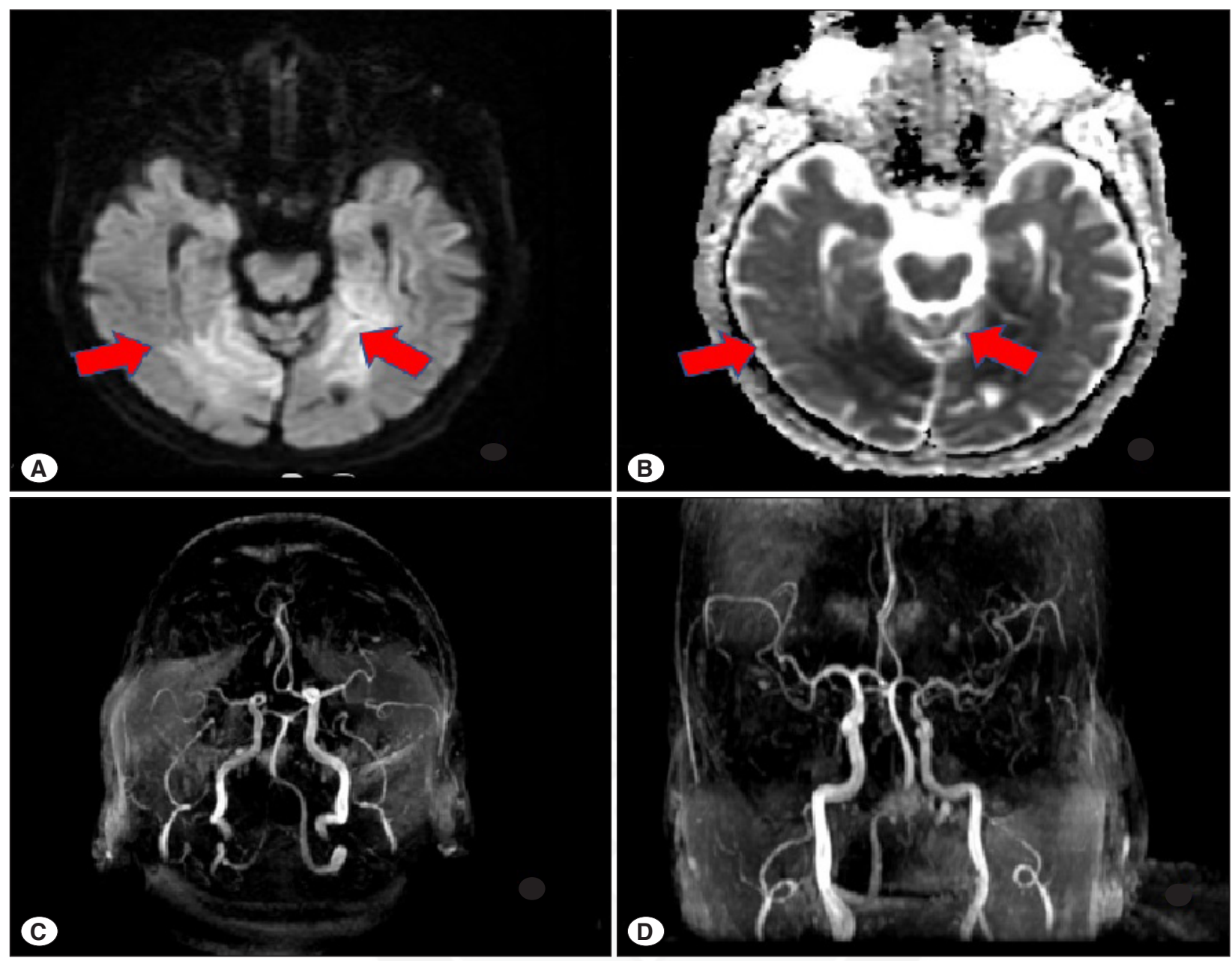

Şekil 1: Hastanın beyin difüzyon manyetik rezonans ve manyetik rezonans anjiografi görüntüleri.

Beyin difüzyon manyetik rezonans görüntülemesinde bilateral oksipital akut enfarkt görüldü $(\mathbf{A}, \mathbf{B})$. Manyetik rezonans anjiografisinde bilateral posterior serebral arterde dolum defekti izlendi (C,D).

sendromu olgusunda da sekelsiz iyileşme saptanmıştır (8). Maddula ve ark.nın bildirdiği bilateral oksipital lob enfarktına bağlı Anton-Babinski sendromu vakasında ise hastanın birkaç hafta içerisinde görme keskinliğinde artış olduğu yakınları tarafından bildirilmiştir (2). Yazarlar bu durumun hastanın görme keskinliğindeki azalmayı inkâr etmeye devam etmesinden kaynaklanabileceğini öne sürmüşlerdir. Bununla birlikte Kwong Yew ve ark. 57 yaşında diyabet ve hipertansiyonu olan ve bilateral oksipital lob enfarktı gelişen ve Anton-Babinski sendromu olgusunun taburculuğu sırasında görme keskinliğindeki azalmayı inkâr etmediği bildirmişlerdir (5). Bizim hastamızda taburculuğu sırasında görme keskinliğinde düzelme olmadığı gözlendi.

Hastalar gördüklerini zannettikleri için normal hareket etmeye devam ederler ve travmaya eğilimli olabilirler. Gelişebilecek travmatik komplikasyonlar konusunda hasta yakınlarının eğitilmesi gerektiğini düşünmekteyiz. Anton-Babinski sendromu ile ilgili bildiriler yapılmış fakat pek çok çalışma olgu sunumu düzeyinde olabilmiştir. Bunun yanında trombolitik ve trombektomi tedavisinin uygulanıp uygulanmadığı konusunda yeterli bilgi verilmemiştir. Anton sendromunun her ne kadar nöropsikiyatrik bir sendrom olduğu düşünülse de geniş çaplı çalışmalara intiyaç duyulmaktadır.

Anton sendromu kortikal körlük ve bu durumun hastanın kabul etmemesiyle karakterize nadir bir antitedir. Anton sendromunu erken farketmek trombolitik tedavi verilmesi açısından fırsat yaratabilir. Taburculukta gelişebilecek travmatik komplikasyonlara karşı hasta ve bakıcıları eğitilmelidir.

\section{Teşekkür}

Yoktur.

\section{Yazar Katkı Beyanı}

Tüm yazarlar yazının fikir, tasarım, denetleme, kaynak taraması, analiz- yorum, makale yazımı, eleştirel inceleme aşamalarında katkı sunmuştur. 


\section{Çıkar Çatışması}

Herhangi bir çıkar çatışmamız yoktur

\section{Finansal Destek}

Olgu sunumumuz ile ilgili olarak finansal destek alınmamıştır

\section{Etik Kurul Onayı ve Onam}

Olgu sunumu olduğu için etik kurul oluru gerekmemiştir. Sözlü ve yazılı hasta onamı alınmıştır.

\section{Hakemlik Süreci}

Kör hakemlik süreci sonrası yayınlanmaya uygun bulunmuş ve kabul edilmiştir.

\section{KAYNAKLAR}

1. M Das J, Naqvi IA. Anton Syndrome. In: StatPearls [internet yayını]. Treasure Island (FL): StatPearls Publishing; 2020 Jan[Atıf 2020.10.13]. Erişim: https://www.ncbi.nlm.nih.gov/books/ NBK538155/
2. Maddula M, Lutton S, Keegan B. Anton's syndrome due to cerebrovascular disease: A case report. J Med Case Rep 2009;3:9028.

3. Misra M, Rath S, Mohanty AB. Anton syndrome and cortical blindness due to bilateral occipital infarction. Indian $\mathrm{J}$ Ophthalmol 1989;37(4):196.

4. McGlynn SM, Schacter DL. Unawareness of deficits in neuropsychological syndromes. J Clin Exp Neuropsychol 1989;11(2):143-205.

5. Kwong Yew K, Abdul Halim S, Liza-Sharmini AT, Tharakan J. Recurrent bilateral occipital infarct with cortical blindness and anton syndrome. Case Rep Ophthalmol Med 2014;2014:795837.

6. McGlynn SM, Schacter DL. Unawareness of deficits in neuropsychological syndromes. J Clin Exp Neuropsychol 1989;11(2):143-205.

7. Dornak T, Kral M, Sanak D, Kanovski P. Intravenous thrombolysis in posterior circulation stroke. Front Neurol 2019;10:417.

8. Roos KL, Tuite PJ, Below ME, Pascuzzi RM. Reversible cortical blindness (Anton's Syndrome) associated with bilateral occipital EEG abnormalities. Clin Electroencephalogr 1990;21(2):104109. 